\title{
ATUALIZAÇÃO DA GRAMÁTICA HABITACIONAL NO RIO DE JANEIRO: A ELEIÇÃO DE CRIVELLA E A SUPOSTA RETOMADA DO DISCURSO DE URBANIZAÇÃO
}

Breno Botelho*

\section{Resumo}

Neste artigo comparo os enfoques entre políticas públicas habitacionais, na cidade do Rio de Janeiro, nas gestões de Eduardo Paes (2009 a 2016) e Marcelo Crivella (2017 à 2019). Filiando-me ao conceito de gramática habitacional de Magalhães (2013), utilizando metodologia qualitativa de observação direta, baseada em três anos de trabalho de campo, e análise documental. Trago como hipótese a atualização da gramática habitacional no município.

\section{Palavras-chave}

Urbanização. Remoção. Favelas. Rio de Janeiro. Habitação

\section{1) Introdução}

Tendo como foco analisar a transformação do repertório das políticas públicas habitacionais na cidade do Rio de Janeiro, filiando-me ao conceito de gramática habitacional de Magalhães (2013), neste artigo comparo duas gestões municipais: Eduardo Paes (2009 à 2016), e Marcelo Crivella (2017 à 2019) ${ }^{1}$, e suas respectivas atuações neste setor. Em minha experiência de campo e interação com algumas das organizações e movimentos sociais que serão citados ao longo deste trabalho, observei ao longo dos dois primeiros anos da gestão de Crivella um sentimento comum quanto a uma possível ausência de intervenções da gestão municipal em relação à moradia nos territórios de favelas. Essa percepção que, em grande medida, se expressava em forma de alívio pelos sujeitos destes movimentos e organizações - tendo em vista a comparação sempre feita com uma excessiva política de remoções ${ }^{2}$ da gestão municipal anterior -,

\footnotetext{
* Mestrando em Sociologia pelo PPGS da UFF, graduado em Ciências Sociais pela UFRJ. Membro do grupo de pesquisa de História do Catolicismo LHER-UFRJ.

${ }^{1}$ Este artigo foi escrito antes do final da primeira gestão do Prefeito Marcelo Crivella, por este motivo a análise aqui empreendida se restringe aos anos de 2017 à início de 2019 de sua gestão.

${ }^{2}$ Publicado em 2015 pela ONG de direitos humanos Justiça Global, o relatório do Comitê Rio Copa e Olimpíadas, que foi baseado em dados oficiais disponibilizados pela prefeitura, apontava que entre os anos de 2009 e 2015 um total de 22.059 famílias, totalizando 77, 206 pessoas, haviam sido removidas somente no município do Rio. Sendo este o maior volume de remoções verificadas na história do Rio de Janeiro (JUSTIÇA GLOBAL, 2015).
} 
camufla uma nuance importante da transição que vem se operando, que espero neste trabalho poder explorar de forma inicial.

Trago como hipótese o reposicionamento discursivo sobre a política pública de habitação nos territórios de favelas, baseado em três frentes principais que atuam para o retorno da urbanização como gramática privilegiada de política pública, em detrimento do enfoque remocionista vigente na gestão anterior. Recorro, para tanto, a uma metodologia principalmente qualitativa, de observação direta, explorando, dentre outros elementos, situações sociais que me permitiram refletir as dinâmicas envolvendo múltiplos atores, à exemplo de Gluckman (1987). O trabalho contou com a experiência de campo entre os anos de 2015 à 2018 na comunidade Vila Autódromo, localizada na zona Oeste do Rio de Janeiro, e pontualmente em outras comunidades; contou com acompanhamento de seminários, reuniões (dentre elas as do conselho popular ${ }^{3}$ entre os anos de 2018 e 2019); com debates realizados em distintos locais, envolvendo múltiplos agentes sociais, como moradores, representantes públicos, movimentos sociais, religiosos, dentre outros. E, também, contou com a realização de entrevistas e análises documentais de reportagens e relatórios, produzidos por estes distintos agentes.

A estrutura deste artigo segue o seguinte padrão: inicialmente apresento uma análise das políticas habitacionais no município carioca, na qual descrevo um breve apanhado histórico das principais vertentes de intervenção pública na moradia de favelas, ressaltando que remoção e urbanização disputam destaque nas retóricas e ações dos agentes públicos até a década de 1990. Em seguida, exponho um panorama dessas intervenções a partir dos anos 2000, em que a gestão de Eduardo Paes desponta como o maior volume de remoções da história do Rio de Janeiro (AZEVEDO; FAULHARBER, 2015). Nesse contexto, apresento um relato da experiência de reurbanização ocorrida na comunidade Vila Autódromo durante o período das Olimpíadas do Rio, e como a partir dela, bases técnicas foram criadas para modelos alternativos às remoções, em paralelo ao fortalecimento de frentes políticas antirremocionistas. Na última parte do artigo, faço uma

\footnotetext{
${ }^{3}$ Conselho criado no contexto dos megaeventos esportivos e ligado à Pastoral de Favelas da Igreja Católica. O conselho é um espaço organizativo que reúne diversos atores políticos em busca por soluções para conflitos fundiários urbanos, tais como: o núcleo de terras da Defensoria Pública, o ITERJ, alguns parlamentares municipais e estaduais, movimentos sociais, representantes religiosos, advogados, lideranças comunitárias, dentre outros. Suas reuniões ocorrem quinzenalmente, alternadamente entre a sede da arquidiocese do Rio, localizada na Mitra Episcopal da Glória, e em comunidades distintas, cujos moradores são membros do conselho.
} 
leitura da gestão Crivella sobre o tema, apontando para uma guinada discursiva próurbanização, e, portanto, uma reatualização da gramática habitacional.

Por fim, a noção de gramática a qual me filio neste trabalho tem como premissa a ideia de que as mudanças no cenário político e social exigem dos sujeitos envolvidos em conflitos fundiários, sejam eles moradores, governantes etc. uma permanente adequação discursiva com fins a ajustar seus objetivos mais imediatos aos imperativos mais gerais, econômicos ou culturais, que tencionam tais disputas. Neste sentido, toda a mobilização do conceito de gramática habitacional neste trabalho baseia-se no seguinte pressuposto:

para compreender os significados assumidos pelo vocábulo 'remoção' atualmente na configuração assumida pelo conflito social no Rio de Janeiro, é necessário levar em consideração os usos em que está envolvido, isto é, como é agenciado na vida cotidiana [...]. Gramática, portanto, refere-se ao conjunto de restrições aos quais os indivíduos devem considerar em cada situação em que se encontram envolvidos. A apreciação dos constrangimentos impostos em uma dada situação reflete o esforço do ator em se adequar ao contexto, mesmo que através da mobilização de alguma crítica." (MAGALHÃES, 2013, p. 78)

\section{2) Políticas públicas habitacionais em favelas cariocas: um breve resgate histórico}

Neste tópico veremos que, constituído historicamente como um verdadeiro laboratório das políticas habitacionais urbanas, a cidade do Rio de Janeiro apresenta um amplo aspecto de transformações dessas políticas que, de certa forma, refletem as próprias transformações do ambiente político e as percepções sobre os territórios de favelas e as populações carentes. A aplicação de dois padrões de interferência nas políticas públicas habitacionais em favelas consolidaram-se ao longo da história da cidade, ora privilegiando as remoções, ora favorecendo a urbanização, ou mesmo coexistindo as duas frentes como aponta Machado da Silva (2016). Na década de 1980, a eleição de Brizola ao governo do Estado abre uma frente contra as remoções em massa e estabelece um padrão de percepção negativa quanto à prática de remoções no Rio; com o início dos anos 2000 um padrão de reversão dessa percepção pública é operado, reatualizando a gramática das remoções como aponta Magalhães (2013), dando início a um período que fica marcado como o maior volume de remoções da história da cidade, o período de preparação para os megaeventos.

O município do Rio de Janeiro se insere em posição privilegiada para a análise de conflitos sociais relativos à reestruturação do espaço físico urbano em decorrência da 
realização de inúmeros megaeventos (tais como: Pan-Americano, Copa do Mundo, Olimpíadas etc.), mas também pelo histórico de modificações de políticas públicas habitacionais empreendidas na cidade. Para Machado da Silva (2016), a questão da moradia popular urbana já se apresentava como uma preocupação nas principais cidades brasileiras desde o início do século passado, referindo-se, principalmente, a dois focos: a necessidade de abrigar a força de trabalho especializada do período de industrialização e as condições degradantes de habitações coletivas existentes nas classes populares, sendo as primeiras intervenções de cunho basicamente sanitaristas. Será a partir da década de 1930, segundo aponta o autor, que o crescimento das favelas na cidade, então capital Federal, ganharia maior impulso - em função do fortalecimento da industrialização e criação de um intenso processo de urbanização. No entanto, a favelização só se transformaria em problema acadêmico e político mais sério vinte anos depois.

Machado da Silva (2016) apresenta um histórico do desenvolvimento das políticas habitacionais para as favelas destacando as vertentes privilegiadas em cada contexto histórico e político. Dessa forma, podemos acompanhar a criação do Código de Obras, no primeiro período Varguista que, ao não reconhecer oficialmente a existência destas localidades passou a lhes conferir, pela primeira vez, o status da ilegalidade (que se expressa até os dias de hoje na percepção pública sobre as favelas). Paralela à proibição de construções de novas casas nesses territórios considerados ilegais, e também de melhorias nas já existentes. Cria-se, no começo da década de 1940, os parques proletários, apontados pelo autor como a primeira consequência prática dessa nova orientação Varguista, estes eram apontados como meio "seguro" para a extinção das favelas.

No entanto, o fim da ditadura Vargas e a redemocratização levam ao abandono dessa política em 1945, embora continuassem as restrições previstas no Código de Obras de 1937. Entrará em cena a Igreja Católica através da Fundação Leão XIII, criada por decreto presidencial em 22 de janeiro de 1947 e subordinada à Diocese do Rio de Janeiro. Com cunho assistencialista, previa inicialmente, uma orientação para a urbanização ${ }^{4}$, no entanto, forma-se a compreensão de que seu papel estratégico era muito mais frear a inserção do Partido Comunista nas favelas. Em análise sobre a atuação estratégica da Fundação, Robaina (2013) aponta uma dupla intervenção que, ao tempo em que promovia melhorias estruturais nas comunidades, também desenvolvia mecanismos de controle e

\footnotetext{
${ }^{4}$ Para mais informações sobre as criações, e atuações, da fundação Leão XIII e Cruzada São Sebastião ver: Valladares (1978); Leedes e Leeds (1987); Robaina (2013); Machado da Silva (2015); Magalhães (2013), dentre outros.
} 
monitoramento das organizações de base dos comunistas, como fica claro na afirmação: "é necessário subir o morro antes que os comunistas desçam" (SAGMACS, 1960 apud LEEDS e LEEDS, 1978).

A década de 1950 é marcada pelo fortalecimento das remoções em larga escala após as experiências de implementação de distintos programas, culminando com a criação da Companhia Estadual de Habitação (COHAB), que seria singular para a efetivação de uma política de remoções em massa. A resposta organizativa dos moradores foi uma das consequências desse processo, que, através da intensificação das mobilizações a partir das associações de moradores, e da criação da Federação das Associações de Moradores do Estado da Guanabara (FAFEG) - que viria a sofrer interferência federal logo após -, intensificaram a denúncia contra as remoções em curso.

Diante dos resultados e da reorientação da Fundação Leão XIII, agora atuando como suporte às políticas de remoção, os católicos rompem com a fundação, uma vez que a orientação geral da Igreja Católica era favorável às políticas de urbanização. A Igreja articularia ainda outra Frente de intervenção na moradia urbana, a chamada Cruzada São Sebastião, criada em 1955 em decorrência da urbanização da favela da Praia do Pinto, localizada na Lagoa Rodrigo de Freitas. Incidindo mais fortemente na disputa dos instrumentos de base com lideranças comunistas, porém, passando a compreender também como central a denúncia ao populismo eleitoral nas periferias e favelas, como aponta Machado da Silva (2015). A Cruzada São Sebastião irá diferir-se da Fundação Leão XIII, fundamentalmente, pela aposta radical nas políticas de urbanização. Enquanto a fundação, sob forte interferência do governo, acaba por tornar-se um importante instrumento de operacionalização das remoções em curso. Vale ressaltar que tanto as associações de moradores quanto outras entidades organizativas gerais, como a FAFERJ (Federação de Favelas do Rio de Janeiro) tiveram suas criações influenciadas pelas políticas dos setores da igreja atentos à questão da moradia urbana e da organização social de bases, no entanto, como aponta o historiador Mário Brum (2005), estes instrumentos eram alvos das políticas populistas, tais como as dos chamados chaguistas ${ }^{5}$, que disputavam suas lideranças em troca de apoio estatal. Em seguida, o período que compreende a Ditadura Militar é caracterizado por uma coexistência das políticas habitacionais, assim define Machado este período:

\footnotetext{
${ }^{5}$ Termo que designava o movimento no entorno das políticas do governador do então Estado da Guanabara, Chagas Freitas, entre os anos de 1971 a 1975, e, posteriormente, governador do Rio de Janeiro, entre os anos 1979 a 1983.
} 
A política de habitação para favela entre 1960 e 1975 será marcada por diferentes linhas de ação governamental, ainda que o período se caracterize pela remoção massiva. [...] Em 1968, coexistem duas orientações. Por um lado, a prática autoritária de remoção sob o patrocínio do BNH tem sequência. Por outro, em função dos compromissos durante a campanha eleitoral, o governo estadual cria um órgão de urbanização de favelas, apresentado como experimental (o que pode significar uma forma de minimizar a plataforma política do governo eleito) (MACHADO DA SILVA, 2016, p. 76-77).

O processo de desgaste do regime militar fez com que as políticas de remoções fossem gradualmente sendo reduzidas. A reabertura democrática ascende uma nova reorganização das favelas em torno das associações de moradores e, gradualmente, as reivindicações acerca da qualidade de vida destas localidades foram ganhando espaço no debate público. Passam a explicitar a necessidade da construção de uma nova mentalidade, relacionada ao trato com as favelas. $\mathrm{O}$ auge dessa reorientação se concretiza com a eleição de Leonel Brizola na década de 1980 para o governo do Estado, com a adoção de duas posturas marcantes e interconectadas, segundo aponta Magalhães (2013): o respeito aos Direitos Humanos, incluindo como medida a proibição de incursões policiais; e a criação e revitalização de infraestrutura nas favelas. Desse modo:

O governo Brizola poderia ser compreendido, aqui, como, simultaneamente, resultando e produzindo este repertório da urbanização, na medida em que expressava um momento do debate (conformado pelo aspecto que o conflito social assumia então), levado a cabo por diversos atores coletivos, especialmente as associações de moradores e movimentos pela reforma urbana, em que a urbanização passaria a figurar como uma medida vista como necessária para a integração destas populações às cidades." (MAGALHÃES, 2013, p. 61)

O período Brizola torna-se central para a consolidação de uma percepção social negativa quanto às políticas públicas de remoção. Esse novo enquadramento operaria de forma tão profunda que as remoções passariam a ser apontadas, segundo Magalhães (2013), como um "tabu", que se estenderia durante todos os governos seguintes, chegando a termo apenas após a eleição de Eduardo Paes, em 2009, com a retomada deste tipo de intervenção. Esta percepção pública - portanto, esta gramática habitacional anti-remoção -, seria, em parte, um fator estabilizador e de contenção das políticas de remoção em massa na década de 1990, ainda que pontualmente, algumas comunidades fossem ameaçadas.

\section{3) As intervenções no século XXI}


As primeiras décadas deste século apresentaram uma crescente nos conflitos por moradia em decorrência do volume de remoções levadas a cabo, principalmente, como aponta Magalhães (2013), no período que compreende as gestões de Eduardo Paes a frente da prefeitura, em decorrência de uma redefinição da gramática de remoção empreendida neste período, a qual abordarei mais detalhadamente adiante. Contabilizando um montante de 22.059 famílias, totalizando 77. 206 pessoas removidas somente durante os anos de 2009 a 2015 (JUSTIÇA GLOBAL, 2015), os governos de Eduardo Paes são apontados como os de maior volume de remoções da história do Rio de Janeiro (AZEVEDO. FAULHARBER, 2015). Há uma compreensão de que estas remoções se inserem em um contexto mais geral de reorganização do modelo de planejamento das cidades. Santos J. e Santos (2012) por exemplo, avaliam que, para além das remoções, estão em curso transformações mais profundas da dinâmica urbana das cidades, que "envolvem, de um lado, novos processos de mercantilização da cidade, e de outro, novos padrões de relação entre o Estado e os agentes econômicos e sociais." (SANTOS J. e SANTOS, 2012, p.288). Esta visão pode ser ligada à análise de David Harvey (2005), que sugere um deslocamento dos mecanismos de gestão das cidades. $\mathrm{O}$ autor sustenta que estar-se-ia assistindo a uma 'reorientação das posturas das governanças urbanas adotadas nas últimas duas décadas nos países capitalistas avançados', onde 'a abordagem administrativa, tão característica da década de 1960', estaria dando 'lugar a formas de ação iniciadoras e empreendedoras, nas décadas de 1970 e 1980 (HARVEY, 2005, p. 167 apud SANTOS J. e SANTOS, 2012, p. 290).

Para a urbanista Raquel Rolnik (2013), ex-relatora especial da ONU para a moradia adequada, vivenciamos uma crise global de insegurança da posse, marcada por diversos fatores econômicos, jurídicos, políticos e ambientais. Estas análises buscam compreender um panorama mais geral das transformações ocorridas no processo de organização e gestão das áreas urbanas, dando aos eventos "localizados", como as remoções, uma perspectiva de compreensão quanto às suas possíveis causas estruturais, tais como as que abordarei adiante.

É neste contexto que o repertório da remoção, de que fala Magalhães (2013), se modelaria de forma mais contundente durante a gestão Paes e as incursões midiáticas impulsionadas pelo Jornal O Globo, com fins à tencionar uma retomada da intervenção estatal sobre os territórios de favela, a partir de uma perspectiva favorável às remoções. 
Isso implicaria, também, em disputar simbolicamente a forma como eram percebidas estas ações por parte da sociedade em geral. Uma das estratégias adotadas pela prefeitura foi apontar a existência de um tabu sobre o tema das remoções. Este tabu teria se constituído a partir de gestões municipais que supostamente teriam adotado ações "populistas”, como a proibição de operações policiais nestes territórios e a permissão para expansão dos mesmos, agravando desta forma o "problema favela", - aludindo à gestão Brizola.

A nova postura seria a retomada das remoções, agora sustentadas em um leque de alegações que iam desde o "legado olímpico" até as áreas de risco. Para tal, era preciso transformar a percepção negativa sobre a remoção e encará-la como parte de uma intervenção "necessária", muito embora esta necessidade nem sempre fosse empiricamente comprovada. "Neste sentido, gostaria de destacar que o processo de redefinição da remoção de favelas como um problema público, ora em análise, envolve a mobilização de um repertório discursivo que sustenta as justificações que (re)legitimam esta prática.” (MAGALHÃES, 2013, p. 78).

Inicia-se a partir daí, um conjunto de remoções que inseriram este período na história das políticas habitacionais do Rio. O Dossiê promovido em maio de 2013 pelo comitê popular Rio Copa e Olimpíadas apontava que, "cerca de três mil famílias situadas na cidade do Rio de Janeiro já foram removidas, e outras oito mil estão ameaçadas." (2013, p. 20). Na publicação SMH 2016: remoções no Rio de Janeiro olímpico, podemos encontrar o mapeamento das remoções referentes ao período da primeira gestão do prefeito Eduardo Paes, na qual somente durante os anos 2009 e 2013 foram removidos mais de 65 mil pessoas, número maior que as gestões de Pereira Passos e Carlos Lacerda, juntos (AZEVEDO; FAULHARBER, 2015). Outros dados desse processo são trazidos pelo relatório anual de conflitos urbanos produzido pelo Observatório de Conflitos Urbanos na Cidade do Rio de Janeiro que em 2014 registrou o maior número de conflitos por moradia de todos os 22 anos mapeados pelo Observatório:

A insatisfação com a política de remoção dos governos Estadual e Municipal para a realização dos megaeventos (Copa do Mundo e Olimpíadas) e elitização e gentrificação da cidade é crescente e tem se manifestado, principalmente, na forma de manifestação em praça pública. Esse padrão se manteve e se intensificou durante o ano de 2014, culminando com o maior número de conflitos registrados durante os 22 anos de análise" (2015, p. 58). 
Embora Eduardo Paes apresentasse em seu discurso um "legado olímpico" deixado por sua administração, a extensão dos territórios removidos foi um dos argumentos mais mobilizados durante a campanha eleitoral de 2016 por seus adversários políticos, como forma de acentuar o simbolismo negativo deste legado. Ainda que não nos seja possível afirmar que peso teve o legado de remoções para que o candidato apoiado por Paes, para ser seu sucessor no comando da prefeitura, tenha perdido ainda no primeiro turno, fato é, que todos os demais candidatos adotaram como estratégia a crítica ao seu governo e, desta forma, assumir discursos que simbolizem práticas opostas às adotadas por Paes - como o famoso bordão "vamos cuidar das pessoas", mobilizado por Marcelo Crivella (que ganhou a disputa eleitoral pela prefeitura) -, pode ser compreendido como uma necessidade política de aparentar, mesmo que superficialmente, distanciamento do discurso da intervenção estatal sob a óptica da violência, no caso em tela, das remoções.

\section{4) O caso da Vila Autódromo e a guinada pró-urbanização}

Margeando a lagoa de Jacarepaguá, na Zona Oeste da capital Fluminense, a comunidade Vila Autódromo foi ocupada inicialmente por pescadores na década de 1970, o nome deriva da proximidade com o autódromo de Jacarepaguá, mas a região atualmente foi incorporada à Barra da Tijuca, bairro nobre da cidade. Com a criação da Associação de Moradores e Pescadores da Vila Autódromo (AMPAVA), em 1987, período da administração Brizola, a localidade conquista acesso a serviços públicos essenciais como água encanada, sumidouro, luz elétrica, além de registros formais em órgãos como a Marinha e o Ibama, para regulamentação dos pescadores profissionais ainda residentes. Neste período também se instala na localidade a Igreja Católica, que ganharia papel proeminente na mediação do conflito fundiário posteriormente, sendo atualmente a única construção remanescente da comunidade, que foi demolida e reurbanizada em 2016.

Segundo a publicação do plano popular da Vila Autódromo, responsável pela elaboração do projeto urbanístico apresentado em contraposição às remoções pretendidas pela prefeitura, e elaborado em parceria entre a associação de moradores e núcleos de pesquisas de duas universidades (UFF e UFRJ):

Em 1989 foram assentadas na área várias famílias oriundas da comunidade Cardoso Fontes. Em 1994, a antiga Secretaria da Habitação 
e Assuntos Fundiários do RJ assentou legalmente na Vila Autódromo mais sessenta famílias. Em 1997 centro e quatro famílias receberam titulação do Governo do Estado. Em 1998 os moradores da faixa marginal da lagoa receberam concessão de uso real por noventa anos da antiga Secretaria de Habitação e Assuntos Fundiários do RJ, publicada no D.O de 31/12/98. Em 12/01/2005 a Câmara Municipal do Rio de Janeiro decretou parte da comunidade área de especial interesse social por meio da lei complementar no. 74/2005(PLANO POPULAR DA VILAAUTÓDROMO, 2016, p.8).

Embora todas estas regularizações representassem uma aparente segurança aos moradores quanto à propriedade da terra, a localização da Vila Autódromo em uma área de crescente especulação imobiliária, (Barra da Tijuca, ao lado da atual Vila Olímpica), fez com que os projetos públicos de remoção continuassem sempre na ordem do dia. Ainda em 1992, segundo o Plano Popular, a prefeitura solicita a primeira remoção com base na argumentação de que a localidade causaria "dano estético e ambiental" (2016, p.9). Os megaeventos fundaram uma nova rodada de argumentos que pleiteavam a remoção dos moradores, com tentativas de remoção nos jogos Pan-Americanos de 2007; na Copa do Mundo de 2014 e, mais incisivamente nas Olimpíadas de 2016. Nesta última ocasião, das cerca de 600 famílias, apenas 20 conseguiram permanecer no local, dentre elas a de Dona Penha, importante liderança local, que se tornou símbolo da luta política por moradia urbana no país e no exterior. Sua casa foi demolida no dia em que recebia uma homenagem da Câmara Municipal pelo Dia Internacional da Mulher. Após a demolição, ela passou a residir nas dependências da Paróquia da Igreja Católica, da Vila Autódromo, até que recebesse uma nova casa com a implementação do Plano Urbanístico ${ }^{6}$.

Embora um contingente significativo de moradores tenha sido removido, parte para conjuntos habitacionais, parte para aluguéis sociais, os relatos de moradores durante algumas atividades em que estive presente em trabalho de campo -, denotam que a permanência destas 20 famílias no local é algo extremamente singular para o período. Pois, como fruto de intensas mobilizações políticas, inclusive lutas campais com a Polícia Militar, os moradores conseguiram reverter o projeto inicial da Prefeitura, que previa a demolição e remoção total da comunidade. Esta conquista também só foi viável, porque um conjunto de urbanistas e pesquisadores pró-urbanização apresentaram contra-laudos e a formulação de um projeto Urbanístico Popular, elaborado conjuntamente com os

\footnotetext{
6 Para mais detalhes ver: http://g1.globo.com/rio-de-janeiro/noticia/2016/03/no-dia-em-que-recebehomenagem-mulher-tem-casa-demolida-no-rio.html. Acesso em 16/06/2019.
} 
moradores. Em decorrência de um estágio no Observatório de Conflitos Urbanos, tive a oportunidade de observar algumas etapas da implementação desse projeto na comunidade.

As formas de interações política e social internas e singulares à cada localidade, e as interações entre estas localidades e as instituições supralocais, são essenciais para o entendimento da trajetória das políticas de remoção impetradas nos territórios de favela do Rio de Janeiro. Leeds e Leeds (1997), ao abordarem as relações entre instituições supra locais e as localidades, estabelecem uma análise que nos possibilitou entender as relações entre Estado e territórios de favela, por exemplo, a partir de um marco da não passividade dessas localidades frente às ações estruturais impetradas pelo conjunto de instituições supra locais, que com elas estabelecem algum tipo de vínculo ou influência, como o Estado, a mídia, os agentes financeiros etc.

A caracterização das localidades feita pelos autores supracitados apresenta a característica de um "sistema altamente flexível de adaptação humana" (LEEDS e LEED, 1997) que possibilita uma ágil mobilização e um vasto leque de respostas a contextos e acontecimentos distintos, aos quais possam vir a ser expostos. A capacidade de mobilização de recursos financeiros e sociais, decorrentes da flexibilidade adaptativa das localidades, incide diretamente na capacidade de permanência, não apenas física, mas também dos laços e regras que marcam as interações tanto internas às localidades, como a sua própria existência diante de mudanças no cenário das instituições supralocais.

Machado da Silva (2015), por outro lado, apresenta um panorama onde os estudos relativos às favelas restringiam-se a dois enfoques principais, um buscando traçar "soluções" para o "problema social das favelas" e outro buscando traçar linhas de ação político ideológicas. O primeiro enfoque se sustentaria na premissa de que os territórios de favela seriam um elemento não integrado à sociedade e, dessa forma, suas postulações não só ignoravam a agência dos moradores, como se baseavam na suposição de que estes não seriam capazes de opinar sobre suas próprias condições de habitações. Ficando a encargo das percepções dos agentes externos, da classe média e dos extratos dirigentes as políticas de "integração". O segundo marcar-se-ia pela sua marginalidade em relação ao primeiro. Além disso, os movimentos sociais contestatórios das políticas de remoções estatais, nos períodos analisados por Machado, são apontados como não propositivos, uma vez que, embora se opusessem às remoções, não projetavam nenhuma alternativa enquanto política habitacional. Neste sentido, a elaboração do Plano Popular, como 
relatado acima, contrapõe-se no presente a essa tendência apontada na análise de Machado no passado, e abriu espaço para outros projetos que vem sendo testados, dos quais abordarei adiante.

A mudança das relações entre as localidades e as instituições supralocais, neste caso mais representadas pelo Estado, como abordado acima, estabelecem-se dentro de um cenário que ameaça a estabilidade e aprofunda o desnível nas relações entre estas esferas de representação. Gera um panorama de alteração nas relações de poder que, por sua vez, estimula um constante reajustamento das formas de interação entre estas distintas escalas de representação. Estes reajustamentos iniciados na gestão Paes, como apontado por Magalhães (2013), encontram seu ápice na justificativa de realização dos megaeventos. Mas a trajetória da Vila Autódromo agrega, neste contexto, ainda outra particularidade.

A partir do início dos anos 2000 inicia-se uma nova etapa da disputa fundiária, principalmente no Rio, que concerne à disputa histórica entre os processos de remoção e urbanização. Para o autor supracitado, os acontecimentos que marcaram o início do século contribuíram para uma retomada da intervenção do Estado sobre as localidades de baixa renda sob uma perspectiva da remoção, construindo-se como consequência do novo "repertório da gramática da violência urbana" (MAGALHÃES, 2013, p. 36), a consolidação de um novo discurso, ou "gramática da remoção" (op. cit). Neste sentido, como analisarei mais adiante, a trajetória de mobilização política da Vila Autódromo, que culmina com a conquista da reurbanização da localidade, em lugar de ser apenas um caso isolado, evidencia uma conquista histórica - pois se dá em um momento de tendências favoráveis às remoções. Por isso, acaba por tornar-se um marco, servindo de inspiração para a expansão de frentes que possuem como objetivo a defesa da moradia popular urbana e das políticas de urbanização. Três dessas frentes são:

1- A elaboração de modelos técnicos alternativos às políticas de remoções, como: o "plano de desenvolvimento urbano, econômico, social e cultural" mais conhecido como "Plano Popular". Elaborado em parceria entre o Instituto de Pesquisa e Planejamento Urbano e Regional da UFRJ, e o Núcleo de Estudos e Projetos Habitacionais da UFF, tiveram na Vila Autódromo uma espécie de "implementação experimental", que acabou premiado internacionalmente. Em decorrência da resposta positiva, vem se apresentando como alternativa reivindicada por outras comunidades ameaçadas de remoção, como as Vargens, na Zona Oeste do Rio - em contraposição ao Plano de Estruturação Urbana (PEU), apresentado pela Prefeitura -; e também para a Zona Portuária, no Centro da 
cidade. Este plano marca ainda o fim da postura "não propositiva", abordada anteriormente. Sendo assim:

\begin{abstract}
A mobilização pela regularização de condomínios não é a única luta nas Vargens no que se refere a habitação. No ano passado, após a prefeitura apresentar sua nova proposta para o Plano de Estruturação Urbana (PEU) e a Operação Urbano Consorciada (OUC) da área, um grupo de moradores se uniu em prol do que foi batizado como Plano Popular das Vargens. O objetivo não é apenas se opor ao projeto da prefeitura, mas também oferecer uma alternativa (Reportagem jornal O Globo, acesso em 9/08/2018).
\end{abstract}

Outro instrumento é o Termo Territorial Coletivo (TTC) experiência de regularização fundiária que tem como premissa a gestão coletiva da terra sem supressão da propriedade particular. O modelo teve origem nos Estado Unidos na década de 1960, com o nome de Community Land Trust. No entanto, segundo cartilha elaborada pelo grupo de estudos do TTC no Rio de Janeiro, foi somente na década de 1980 que houve a primeira experiência de implementação do instrumento em área urbana na cidade de Cincinnati, Ohio (EUA). Vem sendo atualmente estudada a sua implementação no Rio. Para tanto, um conjunto de voluntários entre ativistas, urbanistas, pesquisadores, juristas dentre outros estão em avançada articulação com algumas comunidades no intuito de testar a viabilidade de sua implementação no contexto local. O TTC tem como principal foco a delimitação legal da posse compartilhada da terra, gerida por meio de um conselho paritário entre moradores, técnicos e agentes governamentais (podendo sofrer alteração), no qual se subdividem duas categorias de posse: a de superfície, que garante que o dono da casa possa vendê-la individualmente caso queira se mudar do local e a posse do território, de gestão compartilhada, que tem como exclusiva finalidade a moradia social, não podendo ser vendida, portanto, mais blindada às remoções decorrentes do processo especulativo. Segundo cartilha elaborada por este grupo de estudo no Rio:

Uma vez que o proprietário das terras é o TTC, a segurança perante um processo de remoção aumenta dramaticamente, já que a propriedade da pessoa jurídica constituída pela comunidade abrange grande porção de terra-trazendo mais poder de barganha - e que o seu próprio funcionamento implica na auto-organização dos moradores junto a aliados técnicos. Dessa forma, além de ser necessária uma tentativa de remoção de toda a comunidade de uma só vez, o que já dificulta a ação do governo, o conselho de suporte profissional ao TTC aumenta a base de apoio técnico em uma possível tentativa de remoção (2019, p.2). 
2- O fortalecimento das articulações políticas antirremocionistas que ganharam maior visibilidade em decorrência do próprio desgaste das políticas de remoções levadas a cabo pelo ex-prefeito Eduardo Paes. Pertencentes a este grupo podemos citar o Conselho Popular, que surge durante o governo Paes; o Núcleo de Terras e Habitação da defensoria Pública (NUTH); Frentes parlamentares em defesa da moradia urbana (compostas por parlamentares de distintos partidos, em geral os de esquerda); a Pastoral das Favelas da Igreja Católica - esta também tendo conseguido, em agosto de 2018, o Registro Geral de Imóveis (RGI) da comunidade Chácara do Catumbi, após entrada de ação de uso capião coletivo; e por fim, o crescimento e consolidação de movimentos sociais que têm como bandeira central a moradia urbana, tais como MTST, Brigadas Populares, dentre outros.

O conjunto desses movimentos e organizações já realizou, somente no transcurso da primeira gestão Crivella, diversas atividades em torno do fortalecimento de mecanismos de garantia e defesa da moradia popular urbana. Algumas das principais medidas tomadas foram as criações de frentes parlamentares, tanto a nível municipal quanto estadual, que culminaram em diversas audiências públicas já realizadas tanto na Câmara, quanto na Assembléia, assim como acordos coletivos garantindo a integridade dos direitos aos moradores de áreas de risco ou em eminente processo de remoção. Como, por exemplo, o acordo assinado na Câmara Municipal no dia 12 de agosto de 2019 entre moradores da comunidade Muzema, o Ministério Público, a Prefeitura e a Câmara dos Vereadores. O acordo é fruto da mobilização dos moradores, ativistas e parlamentares. ${ }^{7}$

3- E por fim, porém não menos importante, uma possível reorientação da política habitacional adotada pela gestão Crivella, da qual abordarei adiante.

\section{5) A gramática das remoções no contexto pós- megaeventos}

Após todas as idas e vindas que caracterizam o histórico das políticas habitacionais, ora marcado pelas remoções, ora com foco na urbanização - e no interior de cada modalidade dessas um conjunto de interesses conflitantes -, chega-se aos anos 2000, como abordado anteriormente, a uma tendência apontada por Magalhães, principalmente após a eleição do prefeito Eduardo Paes em 2009, onde se instaura uma nova base para a política de remoções, orientada pelos discursos da violência urbana, das

\footnotetext{
${ }^{7}$ Para mais informações sobre a audiência e o acordo acessar: http://www.camara.rj.gov.br/ Acesso em $14 / 08 / 2019$.
} 
áreas de risco e de preservação ambiental, mas também em decorrência, e como justificativa, da realização dos megaeventos esportivos. Esse período, que fica marcado como o de maior volume de remoções da história do Rio, não obstante tenha sido alvo de diversas análises acadêmicas, abre uma interrogação quanto a sua continuidade após a saída de Paes da prefeitura e a eleição de Marcelo Crivella com um suposto discurso antirremoção.

Ao acompanhar uma audiência pública na Câmara dos Vereadores, ocorrida no início de agosto de 2018 para debater a situação das comunidades ainda ameaçadas de remoção na cidade do Rio, pude observar que a Prefeitura, que na ocasião se fazia representar por uma técnica da Sub-secretaria de Habitação, apontava uma "reorientação" da política habitacional adotada na atual gestão. Segundo a técnica, haveria agora uma orientação em favor da urbanização das comunidades, destacando um projeto em andamento subsidiado pelo Banco Interamericano do Desenvolvimento (BID), com fins a urbanização de vinte favelas do município. Ao longo de sua fala termos como "defesa da territorialidade", "local de memória" e "interseccionalidade nas políticas de habitação" eram destacadas como forma a acentuar uma suposta preocupação da Prefeitura com a permanência dos moradores em seus locais de moradia e memória afetiva, por meio de mecanismos de reurbanização integrados em diversas frentes (saneamento, saúde etc.), sempre que possível, na mesma localidade.

Destaco este último aspecto pela relevância que ganha em casos onde a remoção é sustentada como viabilidade após incidentes, como o ocorrido na comunidade da Muzema $^{8}$, Zona Oeste do Rio. Após análise de diversas entrevistas e discursos públicos de Crivella sobre o caso, é possível perceber um enfoque discursivo no reassentamento nas proximidades da comunidade. Tal estratégia, dentre outros pontos, demarca uma posição em relação ao padrão de remoções promovidas no período Paes, onde as comunidades removidas eram reassentadas em áreas muito distantes de suas moradias anteriores, o que tornou-se outro foco de críticas dos movimentos atirremocionistas.

Não é possível, dados os limites deste trabalho, analisar com mais precisão se esta realmente é uma postura efetiva adotada pela gestão Crivella. Mas o fato que me interessa, no entanto, é a perceptível mudança da gramática, de que fala Magalhães, como

\footnotetext{
${ }^{8}$ Após fortes chuvas dois prédios desabaram, vitimando diversas pessoas e levantando um debate sobre a estabilidade técnica dos prédios e do terreno, além da legalidade de suas construções. Para mais detalhes acessar: https://veja.abril.com.br/brasil/dois-predios-desabam-em-comunidade-do-rio-de-janeiro/ acesso em $14 / 08 / 2019$
} 
consequência da transformação mesma do cenário político e do quadro de fatores que conformaram a realidade social carioca pós-megaeventos, e como os novos atores políticos mobilizam este cenário. A tendência agora, no entanto, ocorreria na direção oposta à analisada pelo autor, revalorizando o discurso de urbanização, agora como instrumento por meio do qual se passaria a "cuidar das pessoas".

Por outro lado, se nos dois primeiros anos da gestão Crivella a tendência era de uma aparente apatia quanto à questão habitacional, o ano de 2019 recoloca esta agenda em pauta. Na noite de 6 de fevereiro de 2019, parlamentares cariocas aprovaram a instauração de uma Comissão Parlamentar Mista de Inquérito (CPI) das enchentes. Essa CPI tem como função analisar se o poder público vem cumprindo com a aplicação de recursos e elaboração de estratégias para a contenção das enchentes, ${ }^{9}$ que ocasionaram, no início de 2019, diversos deslizamentos de terras nas favelas do Rio. Como apontado anteriormente, a mobilização de argumentos como "áreas de risco" e "proteção ambiental" passaram a ser articuladas a partir da gestão Paes como justificativa para a remoção em massa de diversas comunidades. Estes argumentos voltam a ganhar ressonância em algumas declarações públicas após as enchentes, ${ }^{10}$ e reacendem a disputa de narrativa entorno do tema.

Ainda em processo inconclusivo, uma das consequências práticas desta CPI foi o levantamento de dados. Constatou-se, a partir de relatório elaborado pelo Tribunal de Contas, que ao longo de seis anos o município deixou de aplicar cerca de 3 bilhões de reais em programas de controle de inundações, contenção de encostas e saneamento ${ }^{11}$.

Tais dados, por fim, passam a ser incorporados pelo conjunto de entidades e movimentos sociais pró-urbanização, aqui descritos, como contra narrativa em defesa da permanência ou garantia de direitos dos moradores localizados em áreas atingidas ou classificadas como de risco. Abre-se, portanto, uma oportunidade de aferir qual a real capacidade de pressão esses agentes políticos terão na delimitação da atual gramática habitacional carioca.

\section{6) Considerações Finais}

\footnotetext{
${ }^{9}$ Para mais detalhes: $<$ https://rioonwatch.org.br/?p=39759> acesso em 16/06/2019.

${ }^{10}$ Para mais detalhes: $<$ https://rioonwatch.org.br/?p=38783> acesso em 16/06/2019.

${ }^{11}$ Para mais detalhes: <https:/g1.globo.com/rj/rio-de-janeiro/noticia/2019/05/11/em-6-anos-o-municipiodo-rio-deixou-de-gastar-r-3-bilhoes-do-orcamento-em-programas-para-conter-os-efeitos-da-chuva-diztcm.ghtml> acesso em 16/06/2019.
} 
As ações de reorientação da simbologia associada às remoções, que ganharam curso acentuado na gestão Paes, aparentam chegar a um declínio com o fim dos megaeventos e sua saída da Gestão Municipal, com uma baixa aceitação política deste legado. Defendi neste artigo que, a partir desta nova configuração política e social, abrese um campo de disputas que recoloca as políticas públicas de urbanização como horizonte viável, operando um reposicionamento discursivo sobre a política pública de habitação nos territórios de favelas, baseado em três frentes principais que atuam para o retorno da urbanização como gramática privilegiada de intervenção, em detrimento do enfoque remocionista vigente na gestão anterior.

São elas: 1- A elaboração, estudos e implementação de modelos técnico -jurídicos alternativos às remoções; 2- O fortalecimento das redes políticas contra as remoções. 3O desgaste político social decorrente do volume de remoções da gestão de Eduardo Paes - que leva a um reposicionamento discursivo na gestão Crivella, na qual o discurso favorável à urbanização se associa ao slogan do "cuidar das pessoas", mobilizado por Crivella como contraposição a uma postura de "descuido", credenciada à antiga gestão em relação aos moradores da cidade.

Por fim, é importante frisar que as reorientações nas políticas habitacionais, e o enfoque dado a um tipo de intervenção não representa a inexistência do outro -assim como apresentei no histórico das intervenções no município -, uma vez que, em maior ou menor grau, toda reurbanização não prescinde uma remoção. São, no entanto, conjunturais e atendem às demandas e pressões de múltiplos agentes, estarão, desta forma, permanentemente em aberto.

\section{Referências}

ALTINO, Lucas. Moradores se unem em prol de plano alternativo ao PEU das Vargens. O Globo Rio, Rio de Janeiro, 03 de Maio de 2017. Disponível em: https://oglobo.globo.com/rio/bairros/moradores-se-unem-em-prol-de-plano-alternativoao-peu-das-vargens-21289352\#ixzz5NtzVhCJZ . Acesso em 09 de Agos. 2018

\section{AZEVEDO, Lena. FAULHARBER. Lucas. SMH 2016: remoções no Rio de Janeiro olímpico: Rio de Janeiro: Mórula, 2015.}

BRUM, Mario Sergio. Despertar e incentivar: A Pastoral de Favelas e o movimento comunitário de favelas cariocas na Redemocratização. Rev. Cantareira. Vol. 2, no 3, ano 3, dez. 2005.

LEEDS, Anthony e LEEDS, Elizabeth. A sociologia do Brasil urbano: Rio de Janeiro: Zahar, 1977. 
MACHADO DA SILVA, Luiz Antonio. Fazendo a cidade: trabalho, moradia e vida local entre as camadas populares urbanas: Rio de Janeiro: Mórula, 2016.

MAGALHÃES, Alexandre de Almeida.Transformações no "problema favela" e a reatualização da "remoção" no Rio de Janeiro. Tese (doutorado). Universidade do Estado do Rio de Janeiro, Instituto de Estudos Sociais e Políticos IESP, 2013.

Megaeventos e violações dos direitos humanos no Rio de Janeiro: Dossiê do Comitê Popular Rio Copa e Olimpíadas, maio, 2013. Disponível em: https://issuu.com/justicaglobal/docs/dossie_comitepopularcoparj_2013. Acesso em: 23 julho. 2018

Megaeventos e violações dos direitos humanos no Rio de Janeiro: Dossiê do Comitê Popular Rio Copa e Olimpíadas, novembro, 2015. Disponível em: https://issuu.com/justicaglobal/docs/dossie_comit rio2015. Acesso em: 23 julho. 2018.

Plano Popular da Vila Autódromo: Plano de desenvolvimento Urbano, Econômico, Social e Cultural: Rio de Janeiro, produção independente, 2016.

Relatório 2015: Observatório de conflitos urbanos na cidade do Rio de Janeiro. 2015. Disponível em:

http://www.observaconflitosrio.ippur.ufrj.br/ippur/liquid2010/analises/relat_2015.pdf. Acesso em: 24 jun.2016

ROLNIK, Raquel. Guerra dos Lugares: a colonização da terra e da moradia na era das finanças: São Paulo: Boitempo, 2015

ROBAINA, Igor Martins Medeiros. Assistência social ou controle sócio-espacial: Uma análise das espacialidades políticas da fundação Leão XII sobre as favelas cariocas (19471962). Revista Espacialidades [online] v. 6, n. 5, 2013.

SANTOS JÚNIO, O.A. SANTOS, M.R.M..Mega eventos e o direito à moradia: questões e reflexões a partir do contexto do Rio de Janeiro. In: OLIVEIRA. CARDOSO. COSTA [et al.] (org.). Grandes projetos metropolitanos: Rio de Janeiro e Belo Horizonte. Rio de Janeiro: Letra Capital, 2012.

SANTOS JÚNIOR, J. A. R. David Harvey e a teoria do desenvolvimento geográfico desigual do capitalismo. Geografia em questão, São Paulo, v. 7, n. 2, p.10-28, 2014.

UPDATING HOUSING GRAMMAR IN RIO DE JANEIRO:

THE ELECTION OF CRIVELLA AND THE POSSIBLE RETURN OF

URBANIZATION SPEECH

\section{Abstract}


In this article I compare the approaches between public housing policies in the city of Rio de Janeiro, under the government of Eduardo Paes (2009 to 2016) and Marcelo Crivella (2017 to 2019). The qualitative analysis undertaken follows Magalhães (2013) concept of "grammar of habitation", using direct observation based on three years of fieldwork and documentary analysis. Results suggest that the municipality's discourse of habitation is revised during the latter period.

\section{Keywords}

Urbanization. Removal. Slum. Rio de Janeiro. Housing 